\title{
The use of biomarkers in detecting subclinical cardiotoxicity in doxorubicin-based treatment for paediatric patients with acute lymphoblastic leukaemia
}

\author{
Letiția Elena Radu',*, Andra Beldiman², Ioana Ghiorghiu, ${ }^{3,4}$, \\ Alina Oprescu ${ }^{5}$, Constantin Arion ${ }^{3}$, Anca Coliță ${ }^{3}$ \\ ${ }^{1}$ Paediatric Haematology and Oncology, Fundeni Clinical Institute, Bucharest, Romania, \\ ${ }^{2}$ Fundeni Clinical Institute, Bucharest, Romania, \\ 3" Carol Davila" University of Medicine and Pharmacy, Fundeni Clinical Institute, Bucharest, Romania, \\ ${ }^{4} V$. Gomoiu Children's Hospital, Bucharest, Romania, \\ ${ }^{5}$ Institute for Cardiovascular Diseases and Transplantation, Tirgu Mures, Romania
}

\begin{abstract}
The international standard protocol for acute lymphoblastic leukaemia (ALL), the most common haemato-oncological pathology at paediatric age, uses anthracyclines as antitumor agents, potentially associated with early or late onset cardiac damage. Currently, echocardiography is the gold standard in the diagnosis of cardiotoxicity, but several biomarkers are evaluated as a possible replacement, pending more extensive clinical studies. We started a prospective study in order to determine the role of two biomarkers, troponin and heart-type fatty acid binding protein, in the evaluation of cardiotoxicity in children over one year of age, diagnosed with ALL. Between February 2015 and April 2016, 20 patients were enrolled and monitored at diagnosis, during chemotherapy and four months after the end of reinduction, through cardiac evaluation and dosing of those two markers in five different points of the treatment protocol. During the first year of follow-up, the patients did not develop clinical signs of cardiac damage, but the study showed a slight increase in troponin levels during chemotherapy, with the return to baseline value after treatment cessation, and also a correlation with the total dose of anthracyclines given to the patient. On the other hand, the second biomarker, heart-type fatty acid binding protein, did not seem to be useful in detecting subclinical cardiac damage in these patients.
\end{abstract}

Keywords: acute lymphoblastic leukaemia;paediatric patients;cardiotoxicity;biomarkers.

Received: $9^{\text {th }}$ January 2016; Accepted: $1^{\text {th }}$ April 2017; Published:14 ${ }^{\text {th }}$ April 2017

\section{Introduction}

Acute lymphoblastic leukaemia (ALL) is the most common malignancy in children and it is associated with an overall event-free survival of around $80 \%$ at 5 years, being the most successful story of modern multi-agent chemotherapy. Short and long-term cardiovascular complications

* Corresponding author: Letiţia Elena Radu, Paediatric Haematology and Oncology, Fundeni Clinical Institute, Bucharest, Romania, e-mail: letitia_radu@yahoo.com 
are well-known side effects of anthracyclines (AC). These include arrhythmias, myocardial ischemia, hypertension, acute heart failure and ventricular dysfunction.

Chemotherapy-induced cardiotoxicity can be divided into three categories: acute, early and late-onset progressive cardiomyopathy [1]. The acute type appears within one week of $\mathrm{AC}$ administration in less than $1 \%$ of the patients. The second form occurs during the first year after treatment in 1.6-2.1\%, while the third type develops after this period. It is estimated that $65 \%$ of cancer survivors present signs of cardiac damage 6 years after treatment [1].

Doxorubicin is more toxic than epirubicin [2]. AC-induced cardiac injury is dose dependent and the international recommendations are not to exceed $450-550 \mathrm{mg} / \mathrm{m}^{2}$ [3], although even lower doses have led to cardiac damage in certain patients [4]. The gold standard for cardiotoxicity detection is serial echocardiography, used prior to treatment initiation and during the course of chemotherapy [5]. Cardiac biomarkers (troponin T, troponin I (TnI), natriuretic peptides, high-sensitivity $\mathrm{C}$ reactive protein, glycogen phosphorylase isoenzyme $\mathrm{BB}$, heart-type fatty acid binding protein (H-FABP), myeloperoxidase, total antioxidant status, circulating microRNAs, creatinine kinase) represent an attractive alternative for the detection of cardiotoxicity and are intensively analysed for many advantages such as being operator-independent, non-invasive and a resource-efficient approach [4].

\section{Objective}

The purpose of this paper was to monitor TnI and H-FABP levels in children diagnosed with ALL, who received a low-dose of AC.

\section{Patients and Methods}

Patients 1 to 18 years of age, newly diagnosed with ALL and treated according to BFM-ALL
IC 2002 protocol, were included in this study, after approval from Fundeni Clinical Institute Ethics Committee. Patients were stratified into three treatment groups: standard risk (SR), intermediary risk (IR) and high risk (HR). After signing an informed consent form, blood for biomarkers analysis was obtained at 5 different moments: (T1) at diagnosis (baseline-TnI1, H-FABP1), (T2) one hour after the first AC administration (TnI2, H-FABP2), (T3) before the last $\mathrm{AC}$ administration (TnI3, H-FABP3), (T4) one hour after the last AC administration (TnI4, H-FABP4) and (T5) one year after diagnosis (TnI5, H-FABP5).

The cumulative dose (CD) of $\mathrm{AC}$ at certain moments was different: at (T2) all patients received $C D$ of $30 \mathrm{mg} / \mathrm{m}^{2}$, at (T3) SR and IR patients received $\mathrm{CD}$ of $210 \mathrm{mg} / \mathrm{m}^{2}$ and $\mathrm{HR}$ patients received $270 \mathrm{mg} / \mathrm{m}^{2}$, at (T4) SR and IR patients received $\mathrm{CD}$ of $240 \mathrm{mg} / \mathrm{m}^{2}$ and $\mathrm{HR}$ patients received $300 \mathrm{mg} / \mathrm{m}^{2}$. In a few cases, AC dose was decreased due to low neutrophil count.

Second generation TnI was assayed on Tosoh Bioscience, AIA-1800 (Immunoassay), with normal range values being $0-0.05 \mathrm{pg} / \mathrm{dl}$.

H-FABP was analysed on calibrated ELISA plate reader using the human H-FABP kit for ELISA (Hycult biotech), the normal range being $0-1.6 \mathrm{ng} / \mathrm{ml}$.

The study was prospective. Characteristics of the study population and biomarker levels were summarized using median, average and range. The statistical analysis was performed using SPSS Statistics 24. Regarding power analysis, we considered a p-value less than 0.05 to be significant, less than 0.001 to be strongly significant and a $\mathrm{p}$ less than 0.0001 to indicate highly statistical value. The data were analysed with Shapiro Wilk normality test. We performed parametric tests: average and median values, standard deviation, paired t-test, one-way Anova and Pearson correlation. 


\section{Results}

The clinical and biological characteristics of the 20 patients included in our study, between February 2015 and April 2016, are presented in TABLE 1.

Most of these features are consistent with the data provided in international studies regarding paediatric patients with ALL. Analysing the age and the leucocyte count using Shapiro Wilk normality test, the results showed that the values were normally distributed. The particularity of our cohort was the high incidence of TEL-AML1 mutation gene $(40 \%)$ and the stratification of our patients only in SR and IR groups. These aspects were found only in children enrolled until April
2016 and analysed in this paper. From May 2016, the patients' characteristics changed: the incidence of TEL-AML1 decreased significantly, many new patients presented BCR-ABL1 and were assigned to the HR group.

TnI levels are detailed in TABLE 2. We performed a Shapiro Wilk normality test on these data: TnI2 was statistically different from the normal distribution, whereas the other measurements proved to be normally distributed. The troponin levels before and after the first dose of AC were the same (TnI 1 vs TnI 2), but we observed a significant difference before and after the last dose of AC (TnI 3 vs TnI 4, p value $0.039)$. There was a highly statistical increase between baseline and $\mathrm{TnI}$ level after the last dose

Table 1. Clinical and biological features of the 20 patients analysed one year after diagnosis; $\mathbf{L}=$ liter; $\mathbf{A L L}=$ acute lymphoblastic leukemia; $\mathbf{P G R}=$ prednisone good responder.

\begin{tabular}{cccc}
\hline Patients' characteristics (total number 20) & Number & $\mathbf{\%}$ \\
\hline & Male & 13 & $65 \%$ \\
\hline Sex & Female & 7 & $35 \%$ \\
\hline Age & $1-5$ years & 14 & $70 \%$ \\
\hline Leucocyte count & $6-15$ years & 6 & $30 \%$ \\
\hline & $<10 x 109 / \mathrm{L}$ & 11 & $55 \%$ \\
\hline & $>10 x 109 / \mathrm{L},<20 \times 109 / \mathrm{L}$ & 7 & $35 \%$ \\
\hline Morphology & $>20 \times 109 / \mathrm{L},<100 \times 109 / \mathrm{L}$ & 2 & $10 \%$ \\
\hline & L1 type lymphoblasts & 17 & $85 \%$ \\
\hline Immunophenotype & L2 type lymphoblasts & 3 & $15 \%$ \\
\hline & B precursor ALL & 17 & $85 \%$ \\
\hline Cytogenetics & T-cell ALL & 3 & $15 \%$ \\
\hline Molecular biology & No anomalies & 15 & $75 \%$ \\
\hline & Hyperdiploidies/mosaicism & 5 & $25 \%$ \\
\hline No fusion genes $*$ & 11 & $55 \%$ \\
\hline Prednisone response & TEL-AML1 & 8 & $40 \%$ \\
\hline Risk group & E2A-PBX1 & 1 & $5 \%$ \\
\hline & PGR & 20 & $100 \%$ \\
\hline & Standard risk & 14 & $70 \%$ \\
\hline & Intermediary risk & 6 & $30 \%$ \\
\hline
\end{tabular}

*fusion genes analysed: TEL-AML1, SIL-TAL1, E2A-PBX1, MLL-AF4, BCR-ABL p190, BCR-ABL p210 
Table 2. Troponin levels for the 20 patients analysed; $\operatorname{TnI} I=\operatorname{troponin} I$; $\operatorname{TnI} 1=$ before the first doxorubicin administration; TnI $2=$ one hour after the first doxorubicin administration; TnI 3=before the last doxorubicin administration; TnI 4=one hour after the last doxorubicin administration; TnI $5=$ one year after diagnosis; vs=versus.

\begin{tabular}{|c|c|c|c|c|c|}
\hline & $\begin{array}{l}\text { Min value } \\
\text { (pg/dl) }\end{array}$ & $\begin{array}{l}\text { Max value } \\
\text { (pg/dl) }\end{array}$ & $\begin{array}{l}\text { Average } \\
\text { value } \\
(\mathrm{pg} / \mathrm{dl}) \\
\end{array}$ & $\begin{array}{c}\text { Median } \\
\text { value } \\
(\mathrm{pg} / \mathrm{dl}) \\
\end{array}$ & Pvalue* \\
\hline TnI 1 & 0.01 & 0.03 & 0.0125 & 0.01 & \\
\hline TnI 2 & 0.01 & 0.03 & 0.0125 & 0.01 & $(\operatorname{TnI} 1$ vs TnI 2$)=1$ \\
\hline TnI 3 & 0.01 & 0.04 & 0.0205 & 0.02 & $(\operatorname{TnI} 3$ vs TnI 4) $=0.039$ \\
\hline TnI 4 & 0.01 & 0.07 & 0.0285 & 0.03 & $(\mathrm{TnI} 1 \mathrm{vs} \mathrm{TnI} 4)=0.001$ \\
\hline TnI 5 & 0.01 & 0.05 & 0.0180 & 0.01 & $($ TnI4 vs TnI 5) $=0.02$ \\
\hline
\end{tabular}

* statistical significance: $\mathrm{p}<0.05$

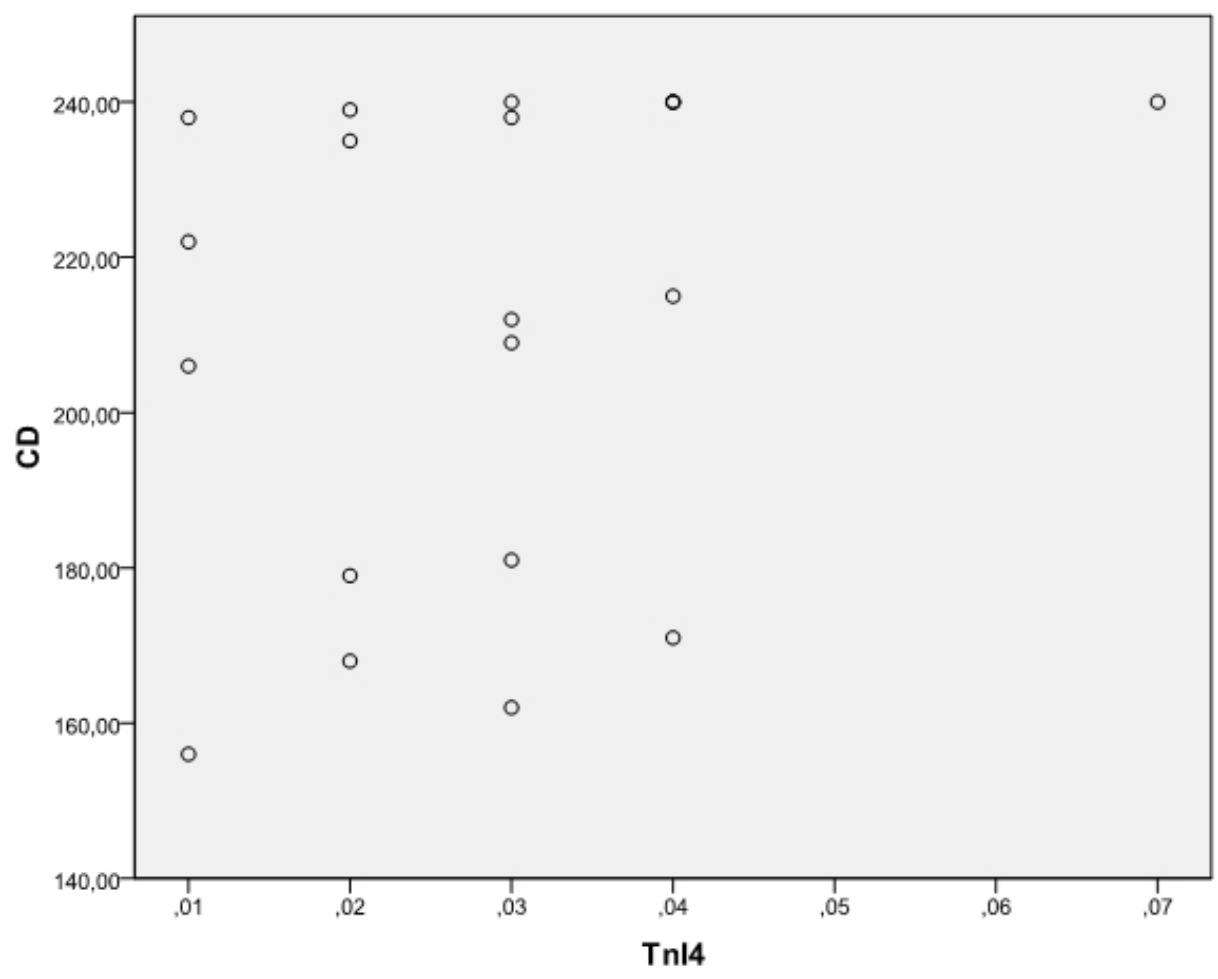

Figure 1. Correlation between TnI4 value (pg/dl) and the CD of AC $\left(\mathrm{mg} / \mathrm{m}^{2}\right)$; TnI4=troponin level after the administration of all doxorubicin doses; $\mathrm{CD}=$ cumulative dose; $\mathrm{AC}=$ anthracycline. 
Table 3. H-FABP levels for the 20 patients who analysed; H-FABP=heart-type fatty acid binding protein; H-FABP 1 =before the first doxorubicin administration;

H-FABP 2=one hour after the first doxorubicin administration; H-FABP $3=$ before the last doxorubicin administration; H-FABP $4=$ one hour after the last doxorubicin administration; H-FABP 5=one year after diagnosis; vs=versus.

\begin{tabular}{|c|c|c|c|c|c|}
\hline & $\begin{array}{l}\text { Min value } \\
\text { (pg/dl) }\end{array}$ & $\begin{array}{l}\text { Max value } \\
\text { (pg/dl) }\end{array}$ & $\begin{array}{l}\text { Average } \\
\text { value } \\
(\mathrm{pg} / \mathrm{dl})\end{array}$ & $\begin{array}{c}\text { Median } \\
\text { value } \\
(\mathbf{p g} / \mathbf{d l})\end{array}$ & P value* \\
\hline H-FABP 1 & 1.48 & 361.7 & 35.84 & 1.84 & \\
\hline H-FABP 2 & 1.59 & 319.1 & 20.48 & 1.85 & $\begin{array}{c}(\text { H-FABP } 1 \text { vs H-FABP } \\
2)=0.331\end{array}$ \\
\hline H-FABP 3 & 0.76 & 239.3 & 17.20 & 1.85 & $\begin{array}{c}\text { (H-FABP } 3 \text { vs H-FABP } \\
4)=0.182 \\
\end{array}$ \\
\hline H-FABP 4 & 1.30 & 190.1 & 12.86 & 1.75 & $\begin{array}{c}\text { (H-FABP } 3 \text { vs H-FABP } \\
4)=0.329\end{array}$ \\
\hline H-FABP 5 & 1.52 & 1.76 & 1.66 & 1.69 & $\begin{array}{c}(\mathrm{H}-\mathrm{FABP} 4 \text { vs H-FABP } \\
5)=0.1\end{array}$ \\
\hline
\end{tabular}

of AC (TnI 1 vs TnI 4, p value <0.0001). In 16 cases $(80 \%)$ the value after the last dose of $\mathrm{AC}$ was higher than TnI at 1 year (TnI 4 vs TnI 5, p value 0.02 ).

We divided the $\mathrm{CD}$ values into 3 groups: 1- less than $190 \mathrm{mg} / \mathrm{m}^{2}$, 2- between 190 and $210 \mathrm{mg} / \mathrm{m}^{2}$, 3- between 210 and $240 \mathrm{mg} / \mathrm{m}^{2}$. We analysed TnI 4 and TnI 5 measurements by using one-way Anova, taking into consideration the three CD groups, but the results were not significant $(\mathrm{f}=0.774$ and $\mathrm{p}=0.477$, respectively $\mathrm{f}=0.273$ and $\mathrm{p}=0.765$ ). Performing Pearson correlation between TnI 4 and CD $\left(\mathrm{mg} / \mathrm{m}^{2}\right)$, we obtained a positive, but weak correlation $(0.276$, p 0.239).

Pearson correlation between Tn4-age and Tn4-number of leucocytes at diagnosis was not statistically significant.

The measurements for H-FABP are detailed in TABLE 3. There was no significant variance immediately after administration of $\mathrm{AC}$
(H-FABP 1 vs H-FABP 2, p 0.331 and H-FABP 3 vs H-FABP 4, p 0.182), after all doxorubicin doses (H-FABP 1 vs H-FABP 4, p 0.329), nor between H-FABP 4 and H-FABP 5, few months after completing the reinduction ( $\mathrm{p} 0.1)$.

\section{Discussion}

The first documentation of cardiotoxicity in patients with ALL was in 1967 and since then, studies have shown that the relative risk of developing cardiotoxicity increases concurrent to the $\mathrm{CD}$ of $\mathrm{AC}$ [6]. After exposure to 151$200 \mathrm{mg} / \mathrm{m}^{2} \mathrm{AC}$, it is associated with odds ratio of 3.69 ; between $201-250 \mathrm{mg} / \mathrm{m}^{2}$ it doubles (odds ratio 7.23) and, when the total dose of doxorubicin rises above $251 \mathrm{mg} / \mathrm{m}^{2}$, the odds ratio reaches 23.47 [7].

It is essential to identify early-on any signs of cardiac damage in patients undergoing chemotherapy for ALL and in long-term survivals. Biomarkers are valuable tools in the 
detection of early-onset cardiac toxicity, being able to assist in the evaluation of low-risk patients and, sometimes, they are considered to have a higher sensitivity to detect cardiac injury than echocardiography.

Troponin is considered the best characterized marker for evaluation of cardiac injury after doxorubicin-based treatment in patients with ALL. In 2004, the FDA concluded that TnI is a sensitive, specific and robust biomarker for cardiac damage, allowing the detection and quantification of cellular damage and death [8]. TnI levels have been shown to increase progressively after more AC doses, being associated with a significantly higher risk of left ventricular dysfunction [5]. Given the low elevations of troponin levels that occur after doxorubicin administration, some studies believe that they may represent physiologic variations [8]. There is no general consensus regarding the use of TnI in detecting and monitoring cardiotoxicity in paediatric patients with ALL.

In our cohort, TnI had the same value at baseline and at one hour after the first dose of AC $\left(30 \mathrm{mg} / \mathrm{m}^{2}\right)$; we obtained a statistical significant increase in TnI before and one hour after the last dose of doxorubicin $(\mathrm{p}=0.039)$, showing that the cardiac damage was more evident as the cumulative dose increases. Moreover, we found a very significant elevation in $\mathrm{TnI}$ at the end of all doxorubicin doses compared to baseline levels $(p<0.0001)$. We performed Pearson correlation, between TnI 4 and CD, resulting in a positive, but weak value, showing that the troponin level was directly proportional with the cumulative dose of doxorubicin given throughout the treatment course. We also performed one-way Anova for TnI4 and TnI5, which returned an insignificant result, suggesting that TnI levels do not vary among the $3 \mathrm{CD}$ intervals. All these can be explained by the low dose of AC used in children's protocol, but also by the small number of patients enrolled in the study. In 16 cases (80\%), the TnI5 was lower than TnI4, suggesting regeneration of myocytes after the cessation of AC administration $(\mathrm{p}=0.02)$.

There are very few studies regarding $\mathrm{H}-\mathrm{FABP}$. It is a low molecular weight protein, found in the cytosol, and it has been more recently developed as cardiac biomarker $[9,10$, 11]. It can be detected as soon as one hour after onset of ischemia and it can be seen as the earliest plasma marker available [12]. In several studies, no correlation between the risk of cardiotoxicity and elevation of H-FABP was found. We did not find a significant increase in H-FABP immediately after doxorubicin administration, after the total dose of AC, nor after one year after diagnosis.

\section{Conclusion}

Cardiac side effects of chemotherapy represent an important evaluation point in ALL patients. Even though the number of children analysed in this paper is small, it is significant for the paediatric patients with ALL treated in our Department.

In this study, we found troponin levels to be correlated with the administration of AC: the value measured after all the AC doses was significantly higher than the baseline. Furthermore, after only four months, the troponin level decreased to the initial value, suggesting there was no permanent damage in cardiac myocytes. Meanwhile, H-FABP does not appear to be useful to detect or monitor doxorubicin-induced cardiotoxicity; therefore, we decided to stop the evaluation of this biomarker in our patients. The study is still open, there are 70 patients enrolled that are being monitored for cardiac damage through changes in TnI levels.

Although clinical manifestations of cardiotoxicity were not encountered in our patients, troponin test should be performed 
at diagnosis, to define a baseline, and during reinduction to establish the patients at risk of developing cardiac damage. Moreover, patients with increased TnI levels during treatment should be carefully monitored further, in order to detect signs of chronic cardiotoxicity. Because the optimal schedule of biomarker assessments remains unknown, prospective clinical trials are needed.

\section{Abbreviations}

\begin{tabular}{|c|c|}
\hline $\mathrm{AC}$ & $=$ anthracyclines \\
\hline ALL & $=$ acute lymphoblastic leukemia \\
\hline BFM ALL & $=$ Berlin-Frankfurt-Munster \\
\hline $\mathrm{IC}$ & $\begin{array}{l}\text { Intercontinental study group } \\
\text { for acute lymphoblastic } \\
\text { leukemia }\end{array}$ \\
\hline $\mathrm{CD}$ & $=$ cumulative dose \\
\hline H-FABP & $\begin{aligned}= & \text { heart-type fatty acid binding } \\
& \text { protein }\end{aligned}$ \\
\hline H-FABP 1 & $\begin{aligned}= & \text { before the first doxorubicin } \\
& \text { administration }\end{aligned}$ \\
\hline H-FABP 2 & $\begin{aligned}= & \text { one hour after the first } \\
& \text { doxorubicin administration }\end{aligned}$ \\
\hline H-FABP 3 & $\begin{aligned}= & \text { before the last doxorubicin } \\
& \text { administration }\end{aligned}$ \\
\hline H-FABP 4 & $\begin{aligned}= & \text { one hour after the last } \\
& \text { doxorubicin administration }\end{aligned}$ \\
\hline H-FABP 5 & $=$ one year after diagnosis \\
\hline HR & $=$ high risk \\
\hline IR & $=$ intermediary risk \\
\hline SR & $=$ standard risk \\
\hline TnI & $=$ troponin $\mathrm{I}$ \\
\hline TnI 1 & $\begin{aligned}= & \text { before the first doxorubicin } \\
& \text { administration }\end{aligned}$ \\
\hline TnI 2 & $\begin{aligned}= & \text { one hour after the first } \\
& \text { doxorubicin administration }\end{aligned}$ \\
\hline TnI 3 & $\begin{aligned}= & \text { before the last doxorubicin } \\
& \text { administration }\end{aligned}$ \\
\hline
\end{tabular}

$\begin{array}{ll}\text { TnI } 4 & =\text { one hour after the last } \\ & \text { doxorubicin administration } \\ \text { TnI } 5 & =\text { one year after diagnosis } \\ \text { Vs } & =\text { versus }\end{array}$

\section{References}

1. Harake D, Franco VI, Henkel JM, Miller TL, Lipshultz SE. Cardiotoxicity in childhood cancer survivors: strategies for prevention and management. Future Cardiol. 2012;8(4):647-70. DOI: 10.2217/fca.12.44

2. Gillespie HS, McGann CJ, Wilson BD. Noninvasive diagnosis of chemotherapy related cardiotoxicity. Curr Cardio Rev. 2011; 7: 234-44. DOI: $10.2174 / 157340311799960672$

3. Vejpongsa P, Yeh ET. Prevention of anthracycline-induced cardiotoxicity: challenges and opportunities. J Am Coll Cardiol. 2014; 64(9): 938-45. DOI: 10.1016/j. jacc.2014.06.1167

4. Tian S, Hirshfield KM, Jabbour SK, Toppmeyer D, Haffty BG, Khan AJ, Goyal S. Serum biomarkers for the detection of cardiac toxicity after chemotherapy and radiation therapy in breast cancer patients. Front Oncol. 2014;4:277. DOI: 10.3389/fonc.2014.00277

5. Christenson ES, James T, Agrawal V, Park BH. Use of biomarkers for the assessment of chemotherapy-induced cardiac toxicity. Clin Biochem. 2015;48(45):223-35. DOI: 10.1016/j.clinbiochem.2014.10.013

6. Van der Pal HJ, van Dalen EC, van Delden E, van Dijk IW, Kok WE, Geskus RB et al. High risk of symptomatic cardiac events in childhood cancer survivors. J Clin Oncol. 2012;30(13):1429-37. DOI: 10.1200/ JCO.2010.33.4730

7. Blanco JG, Sun CL, Landier W, Chen L, Esparza-Duran $\mathrm{D}$, Leisenring $\mathrm{W}$ et al. Anthracycline-related cardiomyopathy after childhood cancer: role of polymorphisms in carbonyl reductase genes- a report forn the Children's Oncology Group. J Clin Oncol. 2012; 30(13):1415-21. DOI: $10.1200 /$ JCO.2011.34.8987

8. Wallace KB, Hausner E, Herman E, Holt GD, MacGregor JT, Metz AL et al. Serum troponins as biomarkers of drug-induced cardiac toxicity. Toxicol Pathol. 2014;32(1):106-21. DOI: $10.1080 / 01926230490261302$ 
9. Azzazy HM, Persers MM, Christenson RH. Unbound free fatty acid-binding protein: diagnosis assays and clinical applications. Clin Chem. 2006;52(1):19-29. DOI: $10.1373 /$ clinchem.2005.056143

10. Liao J, Chan CP, Cheung YC, Lu JH, Luo Y, Cautherley $\mathrm{GW}$ et al. Human heart-type fatty acid-binding protein for on-site diagnosis of early acute myocardial infarction. Int J Cardiol. 2009;133(3):420-3. DOI: 10.1016/j. ijcard.2008.01.049

11. Jacobs LH, van Borren M, Gemen E, van Eck M, van Son B, Glatz JF, et al. Rapidly rule out acute myocardial infarction by combining copeptin and heat-type fatty acid-binding protein with cardiac troponin. Ann Clin Biochem. 2015;52(5):550-61. DOI: $10.1177 / 0004563215578189$

12. Glatz JF, van der Vusse GJ, Simoons ML, Kragten JA, van Dieijen-Visser MP, Hermens WT. Fatty acid-binding protein and the early detection of acute myocardial infarction. Clin Chim Acta. 1998;272(1):87-92. DOI: 10.1016/S0009-8981(97)00255-6 